\title{
ASSESSMENT CONCERNING THE DOMAIN OF APPLICABILITY OF PROTODIAKONOV METHOD IN CALCULUS OF UNDERGROUND STRUCTURES
}

\author{
Adrian POPOVICI - Technical University of Civil Engineering Bucharest \\ Cornel ILINCA - Technical University of Civil Engineering Bucharest \\ Cristian ANGHEL - Technical University of Civil Engineering Bucharest
}

\begin{abstract}
The sectional stresses $(\mathrm{M}, \mathrm{N})$ in a gallery lining are computed comparatively numerical by FEM taking into account the interaction underground structure - surrounding ground and analytical by Protodiakonov method. The last method is based on coincidence arch born in ground over gallery.

Comprehensive analyses allow to settle the domain in which Protodiakonov method can be applied as well as the conditions in which discharge arches appear in ground above underground or embedded structures.

The study is available for galleries (tunnels) built so that their lining takes loads from undeformed ground (rock) mass surrounding gallery, existent before excavation.
\end{abstract}

Keywords: underground structure, interaction, lining, sectional stresses (M, N).

\section{Introduction}

Tunnels (galleries) computation has always been among the most controversial and difficult problem for design engineer. The difficulties in tunnel (gallery) design result from hardness to predict with accuracy ground characteristics due to numerous uncertainties and non-homogeneity. Moreover, these characteristics may change during construction progress or operation.

The construction of an underground (embedded) structure into a mass rock (soil) leads to replacement of the stress state in natural conditions with another stress state generated through the gap excavated in rock mass and its lining [1], [2], [3].

Loading source for lining is surrounding rock mass, but in the same time rock mass is supporting element interacting with lining in order to stabilize a new stress state, this means a new equilibrium state of the new unitary system.

The final equilibrium of the gallery - surrounding rock unitary system depends of an considerable number of factors, the most important being the followings [3], [4]:

- initial stress state in rock mass;

- mechanical characteristics and constitutive laws of rocks (soils);

- stages of execution of the work and their progress over time;

- geometrical and mechanical characteristics of the lining and its connection with adjacent rock

- the conditions concerning construction operation.

Several papers the last decades had been dedicated to compute tunnels (galleries) and their lining by analytical [6], [7], [8] or numerical methods [9], [10]. Some progress were registered in this domain but nowadays this task needs new improved solutions. 
Coming back, strain and stress states in the lining of an underground or embedded structure (tunnels, galleries, caverns) are significantly influenced by the interaction between structure and surrounding ground.

In the of structures surrounded by loose (soft) ground the distribution of loads on structure's lining depends of stiffness rate between the sector limited by vertical planes tangent to gallery lining abutments and lateral sectors (fig.1a). Usually, the stiffness of this sector is higher than of the lateral sectors. As immediate effect, on the sections of separation between sectors are generated downward frictional forces in the sector including structure and equivalent frictional forces upward in lateral sectors. This means that some loads from lateral sectors are transferred to central sectors, respectively to underground structure lining.

Frictional forces in elevation above structure decrease up to zero value, this horizontal plane corresponding to equal settlement plane.

In the case of underground structure built in sound (hard) rocks the interaction between structure and surrounding rock leads to the appearance of some discharge vaults located above the underground structure (fig.1b). Some years ago, Protodiakonov tried to solve this problem considering the surrounding rock as a pulverous material in which a coincidence arch is developed from condition of the sliding stability of the gallery abutments. The material located below the coincidence arch loads on the gallery lining, while the material over the coincidence arch is discharged in lateral sectors by discharge arches.

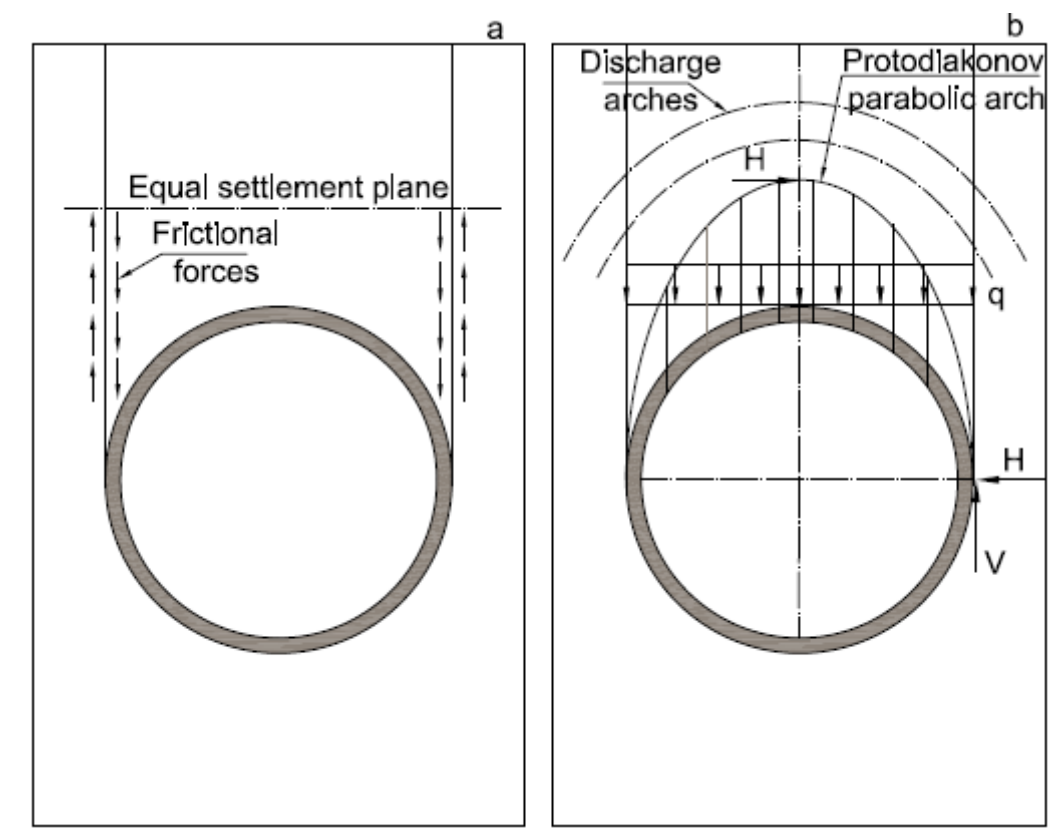

Fig.1 - Schemes of interaction between underground structure and surrounding ground: $\mathrm{a}$ - in soft ground, $\mathrm{b}$ - according to Protodiakonov hypothesis for vertical loads

Although Protodiakonov method assumptions do not correspond with real phenomenon, the method due to its simplicity is still frequently applied in the calculus of galleries (tunnels) lining.

Presently, some more accurate methods are available for galleries lining computation. They are based especially on FEM (Finite Element Method).

In this paper on base of comprehensive computations of a gallery lining through FEM is seeking to settle the field of Protodiakonov method applicability as well as conditions in which are developed discharge arches in ground above the underground or embedded structures. The analysis by FEM of the unitary system ground - gallery is performed in hypothesis of the linear elastic behaviour of materials. 
The study is available only for galleries (tunnels) built by TBM (Tunnel Boring Machine) or other technology, when the lining takes integral loads from undeformed ground (rock) mass surrounding gallery, existent before excavation.

The case of galleries with elastic support (lining) when the intensity of the surrounding rocks pressure develops gradually over time is not the object of this study.

\section{Brief description of Protodiakonov method}

Figure 2 presents the scheme proposed by Protodiakonov to calcule the vertical pressure on an excavation having $b$ width. Protodiakonov considers that due to rock deformation over excavation part of rock can crumble. The limit of the crumble sector will be AOB vault where the tensile stresses are negligible ones, respectively the compressive stresses are in allowable limits. This vault makes up an equilibrium shape of the excavation (coincidence vault). It supports and transfers in lateral sectors the rock weight located over it, while the rock weight located under it constitutes the vertical uniform pressure on excavation (excavation lining).

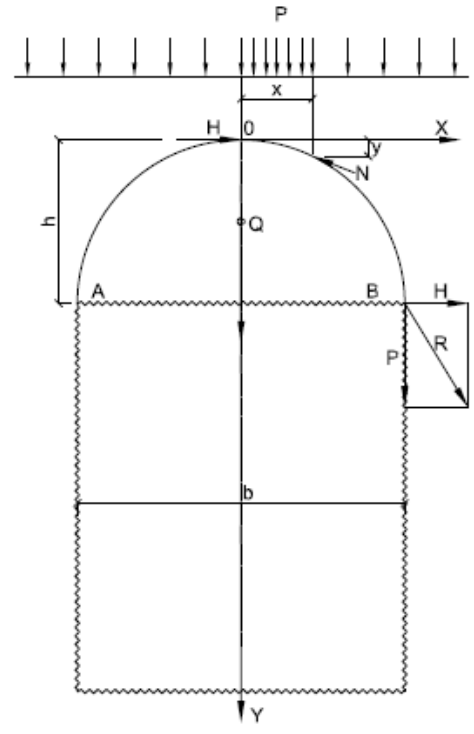

Fig.2 - Scheme for evaluating after Protodiakonov the vertical pressure from surrounding rock on excavation

The shape of an equilibrium vault for a constant vertical pressure is a parabola with equation:

$$
\mathrm{y}=\frac{\mathrm{p}}{2 \mathrm{H}} \mathrm{x}^{2}
$$

where $\mathrm{p}$ is the pressure uniform distributed on horizontal direction, $\mathrm{H}$ - horizontal reaction from vault abutment.

In order to have a stable vault is needs their abutments do not laterally slide. This condition is expressed by relation:

$$
\mathrm{H} \leq \mathrm{f} \mathrm{P}
$$

where $\mathrm{f}$ is frictional coefficient of the rock (named also strength coefficient or Protodiakonov coefficient) and $\mathrm{P}=\frac{1}{2} \mathrm{pb}$ - vertical reaction.

Protodiakonov considers a safety coefficient to sliding equal to 2, resulting:

$$
\mathrm{H}=\frac{1}{4} p b f
$$

Substituting $\mathrm{H}$ in relation (1), finally results:

$$
y=\frac{2 \cdot x^{2}}{b \cdot f}
$$


Taking into account $x=\frac{b}{2}, y=h$ the height of the crumble vault is following:

$$
\mathrm{h}=\frac{b}{2 f}
$$

The total weight of the rock $(\mathrm{Q})$ acting on excavation (excavation lining) results:

$$
\mathrm{Q}=\gamma_{\mathrm{r}} \frac{2}{3} \mathrm{bh}
$$

If $Q$ was uniformly distributed on the excavation width (b) results:

$$
\mathrm{q}=\gamma_{\mathrm{r}} \frac{b}{3 f}
$$

In Protodiakonov method, there is also a methodology for evaluating the horizontal pressure from rock on excavation (gallery walls), that is not subject of this paper and it is not presented.

\section{Results in analyses}

The analyses were carried out numerical by finite element method (FEM) running ABAQUS software [12] and by analytical calculus according to Protodiakonov method using formulas for valuating sectional stresses $(\mathrm{M}, \mathrm{N})$ in gallery lining given in references [1], [2], [4].

In figure 3 is illustrated 2D finite element mesh of the unitary gallery - surrounding ground system. The cross section of the gallery was meshed with 20 linear line beam elements (B21). The surrounding ground was modelled with 2129 linear quadrilateral elements with 4 nodes including incompatible mode (CPS4I) and 64 linear triangular elements (CPS3). The total number of nodes of the mesh was 2277 .

The analyses were carried out for a reinforced concrete circular gallery with $3 \mathrm{~m}$ inner diameter and $25 \mathrm{~cm}$ lining thickness. The surrounding ground had successively different geotechnical characteristics.

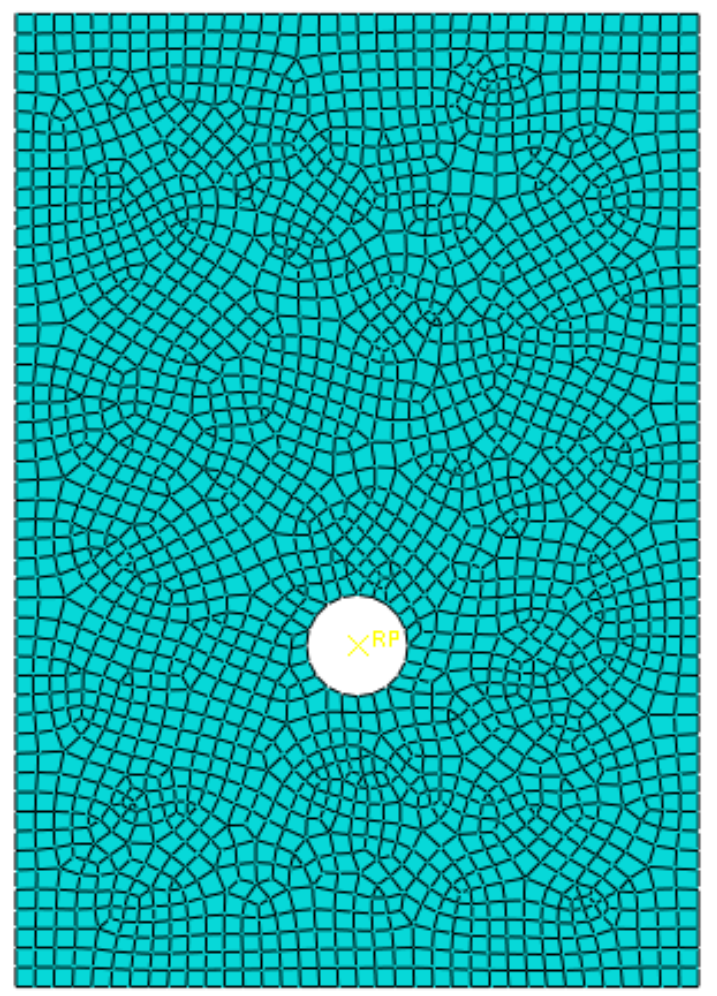

Fig.3 - Finite element mesh (FEM) of the unitary system gallery - surrounding ground 
The mechanical characteristics of the reinforced concrete were $E=24,000 \mathrm{MPa}, \mu=0.20$ and $\gamma_{\mathrm{c}}$ $=24 \mathrm{kN} / \mathrm{m}^{3}$. The geotechnical characteristics of the surrounding ground varied between $6 \mathrm{MPa}$ and 30,000 MPa for Young module, 0.35 and 0.16 for Poisson coefficient and $20 \mathrm{kN} / \mathrm{m}^{3}$ for weight gravity. The weight gravity of the ground was considered invariable in order to mitigate its influence on the results. The effective values of these characteristics can be seen in Table 1 .

The extension of the mesh around gallery reaching 3D $(10 \mathrm{~m})$ on lateral and bottom directions was chosen so that the boundary conditions not to influence the stresses state in the gallery lining. The thickness of the ground over gallery key was $20 \mathrm{~m}$.

Boundary conditions were applied to lateral and bottom edges of the mesh. They consisted in blockage of the node translations in normal direction to edge limits and also of all rotations.

The loads consisted of weights of gallery lining and ground body. The analyses were performed in the gallery cross section for the plane strain state in the hypothesis of the linear elastic behaviour of materials.

Some significant results in the analyses by FEM are illustrated in figures 4 ...10.

Figures 4, 5 and 6 present contour lines in ground (rock) of vertical stresses $\left(\sigma_{\mathrm{v}}\right)$, horizontal stresses $\left(\sigma_{\mathrm{h}}\right)$ and shear stresses $\left(\tau_{\mathrm{xy}}\right)$ around the gallery embedded in sound rock $\left(E_{g}=1000 \mathrm{MPa}, \mu=0.25\right)$ (left figure) and in soft ground ( $E_{\mathrm{g}}=5 \mathrm{MPa}, \mu=0.35$ ) (right figure). As was expected, the unitary stresses $\sigma_{\mathrm{v}}, \sigma_{\mathrm{h}}$ and $\tau_{\mathrm{xy}}$ in ground are all symmetrically ones.
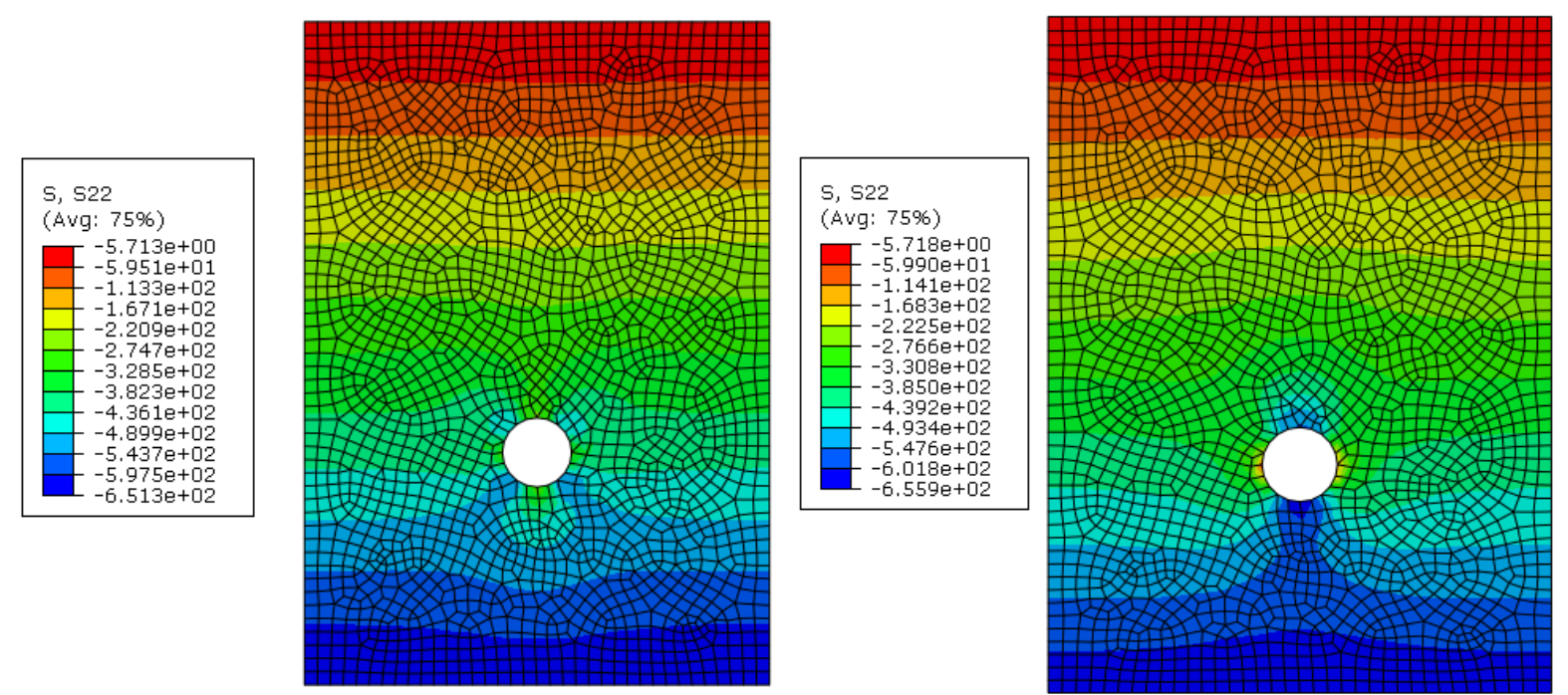

Fig.4 - Contour lines of the vertical stresses (бv) in ground for $\mathrm{Eg}=1000 \mathrm{MPa}, \mu=0.25$ (left figure) and for $\mathrm{Eg}=5 \mathrm{MPa}, \mu=0.35$ (right figure)

Concerning $\sigma_{\mathrm{v}}$ (fig.4) in sound ground, due to the fact that gallery's deformations are small, the lithostatic pressures around gallery lining are less modified than in soft ground case. For instance, $\sigma_{\mathrm{v}}$ in ground near gallery lining abutments $-382 \mathrm{kPa}$ in sound ground case and -114 $\mathrm{kPa}$ in soft ground case. Before gallery construction, in natural condition in that point the lithostatic pressure was $-435 \mathrm{kPa}$. These results points out the gallery lining being much stiffer $\left(E_{c}=24000 \mathrm{MPa}, \mu=0.20\right)$ than surrounding rock, takes important part from rock load, reducing the stresses in rock. 

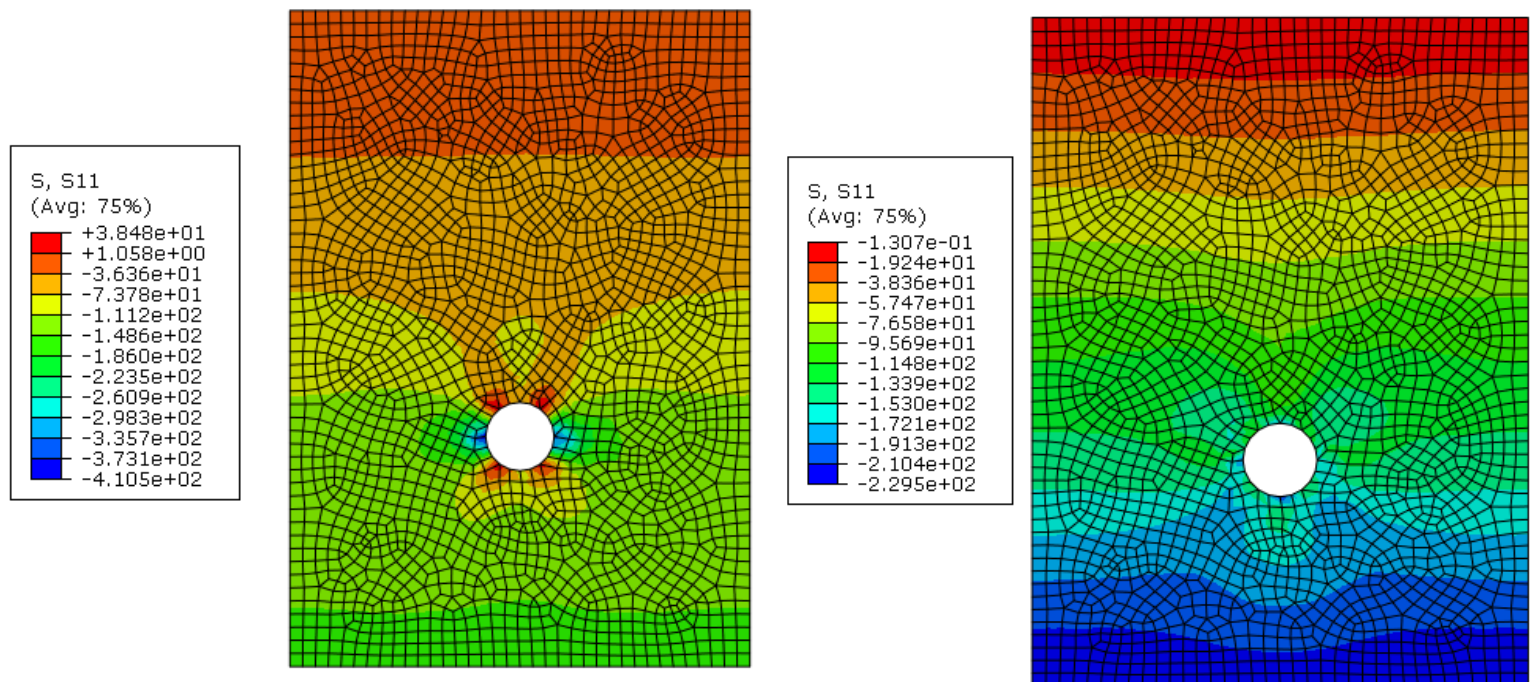

Fig.5 - Contour lines of the horizontal stresses (6h) in ground for $\mathrm{Eg}=1000 \mathrm{MPa}, \mu=0.25$ (left figure) and for $\mathrm{Eg}=5 \mathrm{MPa}, \mu=0.35$ (right figure)

The horizontal stresses, $\sigma_{\mathrm{h}}$ (fig.5) are evidently influenced by ground stiffness. In sound ground the reaction to the elongation tendency on horizontally of the gallery is stronger than in the soft ground case. At gallery lining abutment, $\sigma_{\mathrm{h}}$ reaches $355 \mathrm{kPa}$ in sound ground and respectively $133 \mathrm{kPa}$ in soft ground.
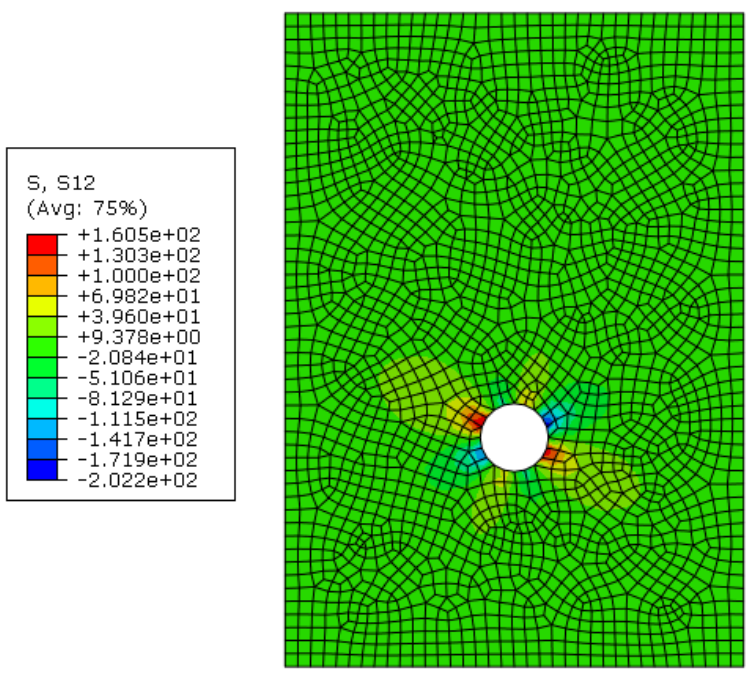

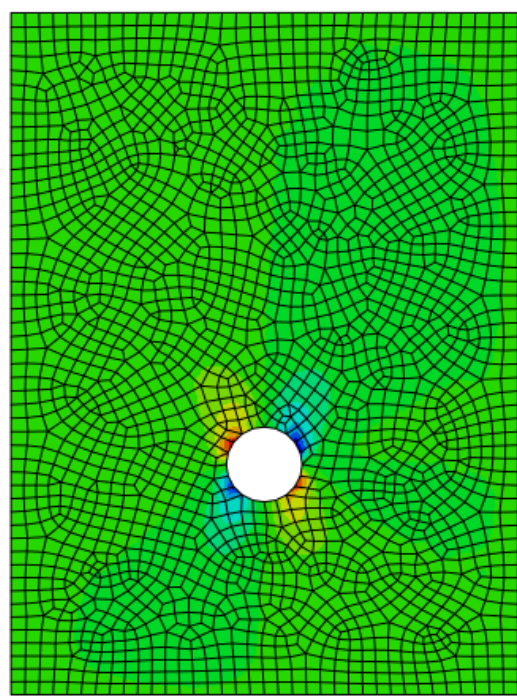

Fig.6 - Contour lines of the shear stresses ( $\tau x y)$ in ground for $\mathrm{Eg}=1000 \mathrm{MPa}, \mu=0.25$ (left figure) and for $\mathrm{Eg}=5 \mathrm{MPa}, \mu=0.35$ (right figure)

The shear stresses $\left(\tau_{\mathrm{xy}}\right)$ (fig.6) are quite symmetrically ones and vary between $+160.57 \mathrm{kPa}$ and $202.20 \mathrm{kPa}$ in sound ground respectively between $+142.90 \mathrm{kPa}$ and $-144.3 \mathrm{kPa}$ in soft ground.

The conclusions concerning $\sigma_{\mathrm{v}}, \sigma_{\mathrm{h}}$ and $\tau_{\mathrm{xy}}$ variation in ground presented above are confirmed by the details of shear stresses $\left(\tau_{\mathrm{xy}}\right)$ and horizontal displacements $\left(\mathrm{u}_{\mathrm{x}}\right)$ around the gallery illustrated in figures 7,8,9 and 10 . 

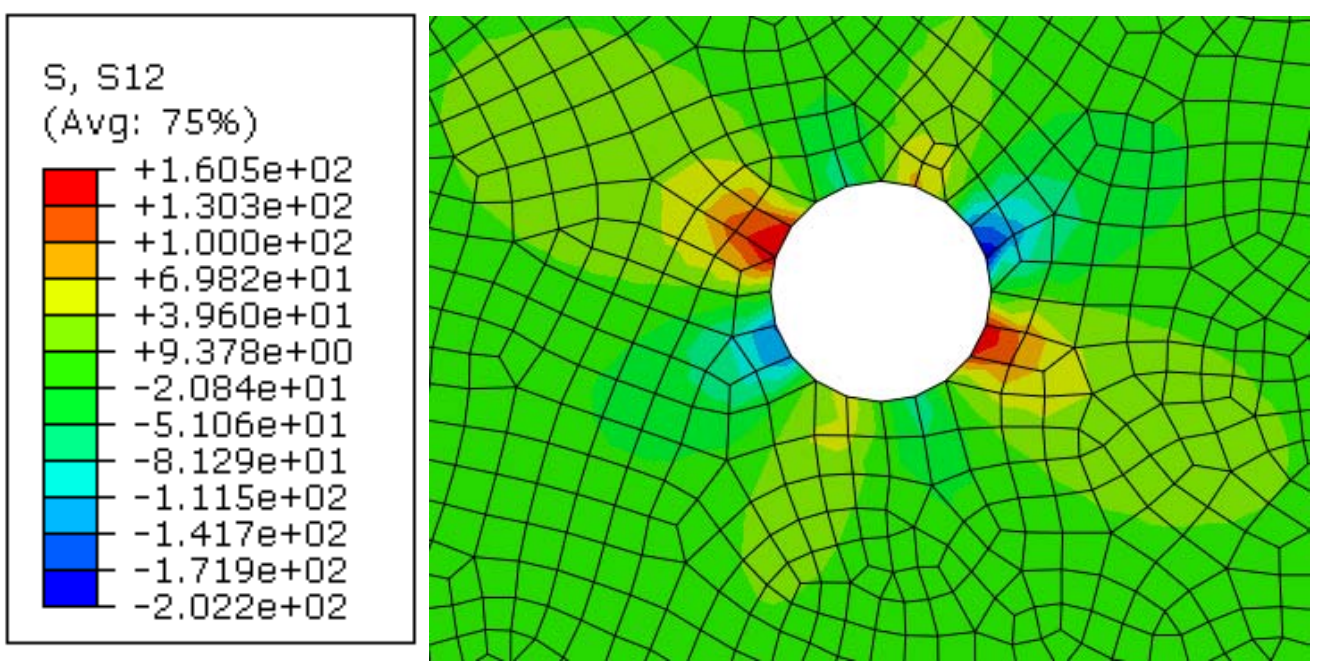

Fig.7 - Details of the shear stresses ( $\tau x y)$ in ground around the gallery for $\mathrm{Eg}=1000 \mathrm{MPa}, \mu=0.25$
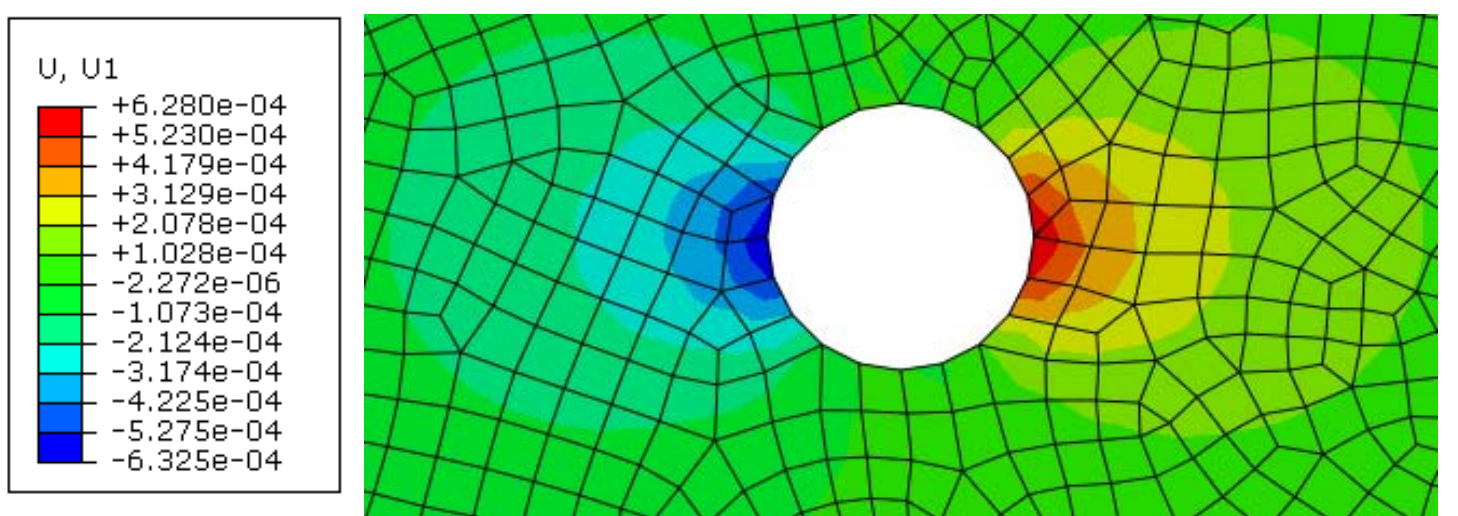

Fig.8 - Details of the horizontal displacementss (ux) in ground around the gallery for $\mathrm{Eg}=1000 \mathrm{MPa}, \mu=0.25$

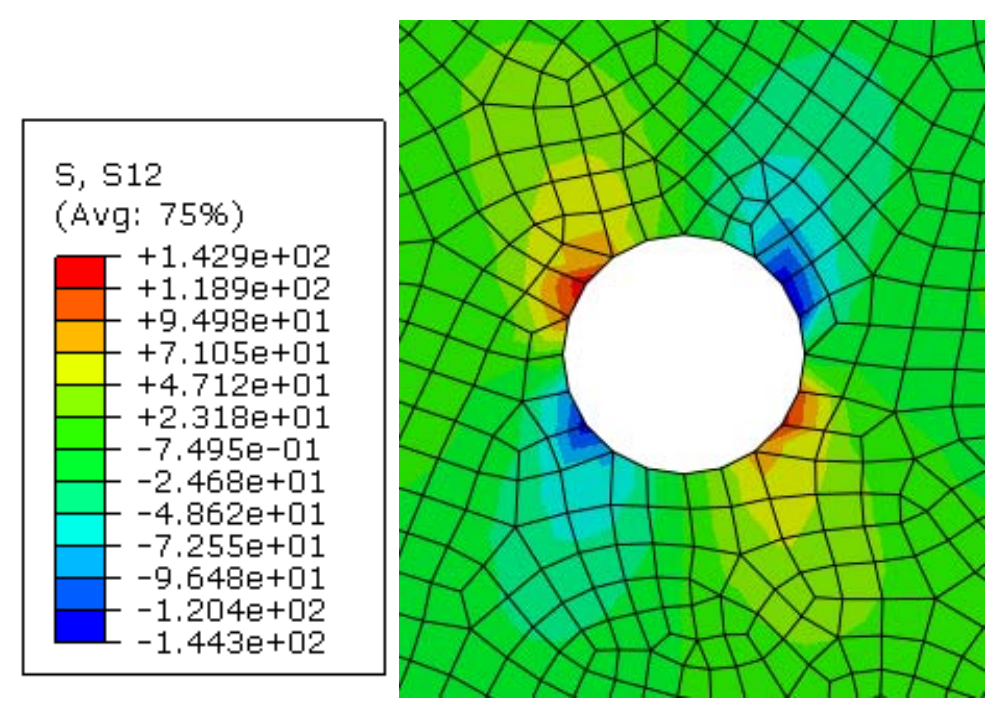

Fig.9 - Details of the shear stresses ( $\tau x y)$ in ground around the gallery for $\mathrm{Eg}=5 \mathrm{MPa}, \mu=0.35$ 

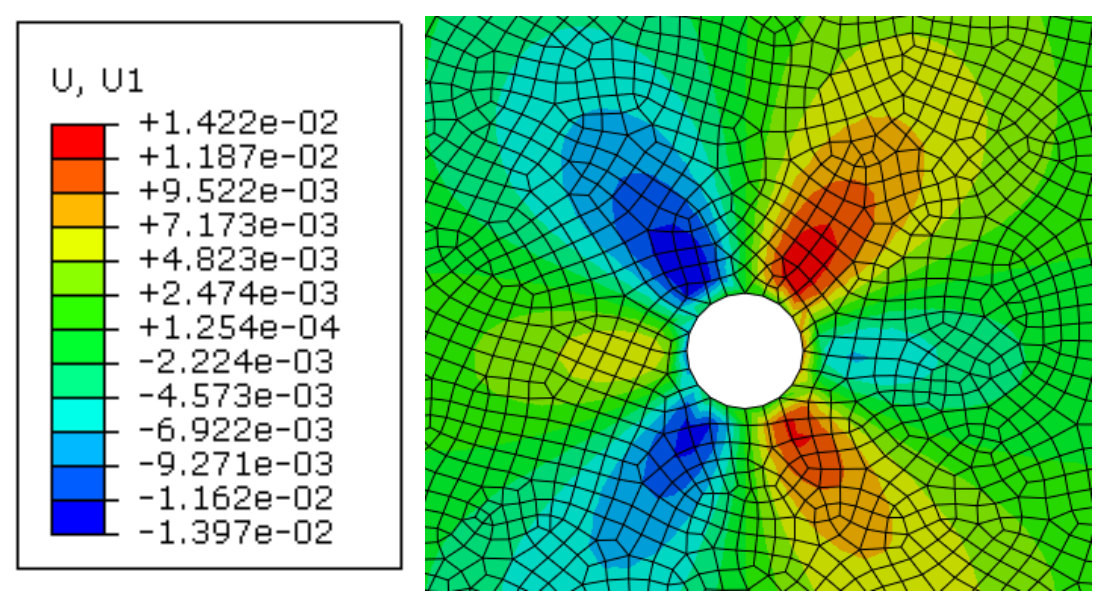

Fig.10 - Details of the horizontal displacementss (ux) in ground around the gallery for $\mathrm{Eg}=5 \mathrm{MPa}, \mu=0.35$

Table 1

Calculul carried out with Finite Element Method (F.E.M.)

\begin{tabular}{|c|c|c|c|c|c|c|c|c|c|c|c|}
\hline \multicolumn{4}{|c|}{$\begin{array}{c}\gamma_{\mathrm{c}}=24 \mathrm{kN} / \mathrm{m}^{3} \\
\mathrm{E}_{\mathrm{c}}=2400 \mathrm{Mpa} \\
\mu=0.2\end{array}$} & \multicolumn{3}{|c|}{$\begin{array}{c}\mathrm{M} \text { - Bending moments } \\
\mathrm{kNm}\end{array}$} & \multicolumn{3}{|c|}{$\begin{array}{l}\mathrm{N}-\text { Axial forces } \\
\mathrm{kN} \\
\text { (-) compression }\end{array}$} & \multicolumn{2}{|c|}{ Lining deformation } \\
\hline$\gamma_{\mathrm{r}}$ & $\mathrm{E}_{\mathrm{r}}$ & $\mu$ & $\mathrm{E}_{\mathrm{c}} / \mathrm{E}_{\mathrm{r}}$ & Key & Abutments & Apron axis & Key & Abutments & Apron axis & $\begin{array}{l}\text { Horizontal } \\
\text { diameter } \\
\text { elongation }\end{array}$ & $\begin{array}{c}\text { Vertical } \\
\text { diameter } \\
\text { shortening }\end{array}$ \\
\hline $\mathrm{kN} / \mathrm{m}^{3}$ & $\mathrm{MPa}$ & & & & & & & & & $\mathrm{cm}$ & $\mathrm{cm}$ \\
\hline 20 & 5 & 0.35 & 0.000208 & 269 & -271 & 276 & -363 & -1069 & -405 & 1.86 & -2.0 \\
\hline 20 & 10 & 0.33 & 0.000416 & 259 & -261 & 266 & -358 & -1071 & -402 & 1.78 & -1.9 \\
\hline 20 & 50 & 0.32 & 0.002083 & 177 & -179 & 184 & -379 & -1046 & -420 & 1.22 & -1.3 \\
\hline 20 & 100 & 0.30 & 0.004167 & 129 & -130 & 134 & -379 & -1033 & -422 & 0.88 & -0.96 \\
\hline 20 & 150 & 0.30 & 0.006250 & 99 & -101 & 105 & -382 & -1017 & -424 & 0.68 & -0.76 \\
\hline 20 & 300 & 0.30 & 0.012500 & 59 & -61 & 63 & -376 & -982 & -418 & 0.40 & -0.46 \\
\hline 20 & 500 & 0.30 & 0.020833 & 38.5 & -40 & 41.54 & -363 & -945 & -400 & 0.24 & -0.2 \\
\hline 20 & 1000 & 0.29 & 0.041667 & 20.55 & -21.3 & 22.6 & -313 & -872 & -349 & 0.12 & -0.20 \\
\hline 20 & 1500 & 0.28 & 0.0625 & 14.06 & -14.33 & 15.58 & -274 & -814 & -303 & 0.08 & -0.14 \\
\hline 20 & 3000 & 0.27 & 0.1250 & 7.16 & -7.76 & 8.10 & -190 & -676 & -212 & 0.04 & -0.08 \\
\hline 20 & 15000 & 0.24 & 0.6250 & 1.44 & -1.51 & 1.68 & -27.48 & -297.9 & -33.78 & 0.00 & -0.04 \\
\hline 20 & 20000 & 0.22 & 0.8333 & 1.10 & -1.15 & 1.27 & -11.37 & -243.4 & -15.92 & 0.00 & -0.02 \\
\hline 20 & 30000 & 0.16 & 1.2500 & 0.78 & -0.80 & 0.90 & 9.67 & -181 & 7.72 & 0.00 & -0.01 \\
\hline
\end{tabular}

The results of some comprehensive analyses by FEM concerning the effects of interaction between gallery and surrounding ground (rock) for different geotechnical characteristics of the ground may be seen in Table 1. The results are presented in sectional stresses $(\mathrm{M}, \mathrm{N})$ and deformations of the gallery. It may remark the important effect of the ground stiffness on sectional stresses in the gallery lining. Increase of the ground stiffness leads to lower sectional stresses in the gallery lining. For instance an increase of the ground Young modulus from $5 \mathrm{MPa}$ to $30,000 \mathrm{MPa}$ leads to decrease of the bending moments $(\mathrm{M})$ at the gallery key from $269 \mathrm{kNm}$ to $0.78 \mathrm{kNm}$.

Under the effect of loads, the gallery becomes oval one. Elongations of the gallery horizontal diameter reach $1.86 \mathrm{~cm}$ for $\mathrm{E}_{\mathrm{g}}=5 \mathrm{MPa}$ and $0.04 \mathrm{~cm}$ for $\mathrm{E}_{\mathrm{g}}=3000 \mathrm{MPa}$. Shortenings of the gallery vertical diameter reach $-2.00 \mathrm{~cm}$ for $\mathrm{E}_{\mathrm{g}}=5 \mathrm{MPa}$ and $-0.04 \mathrm{~cm}$ for $\mathrm{E}_{\mathrm{g}}=3000 \mathrm{MPa}$.

The results of some analyses performed with Protodiakonov method, according to the scheme from figure 11 are presented in Table 2. 

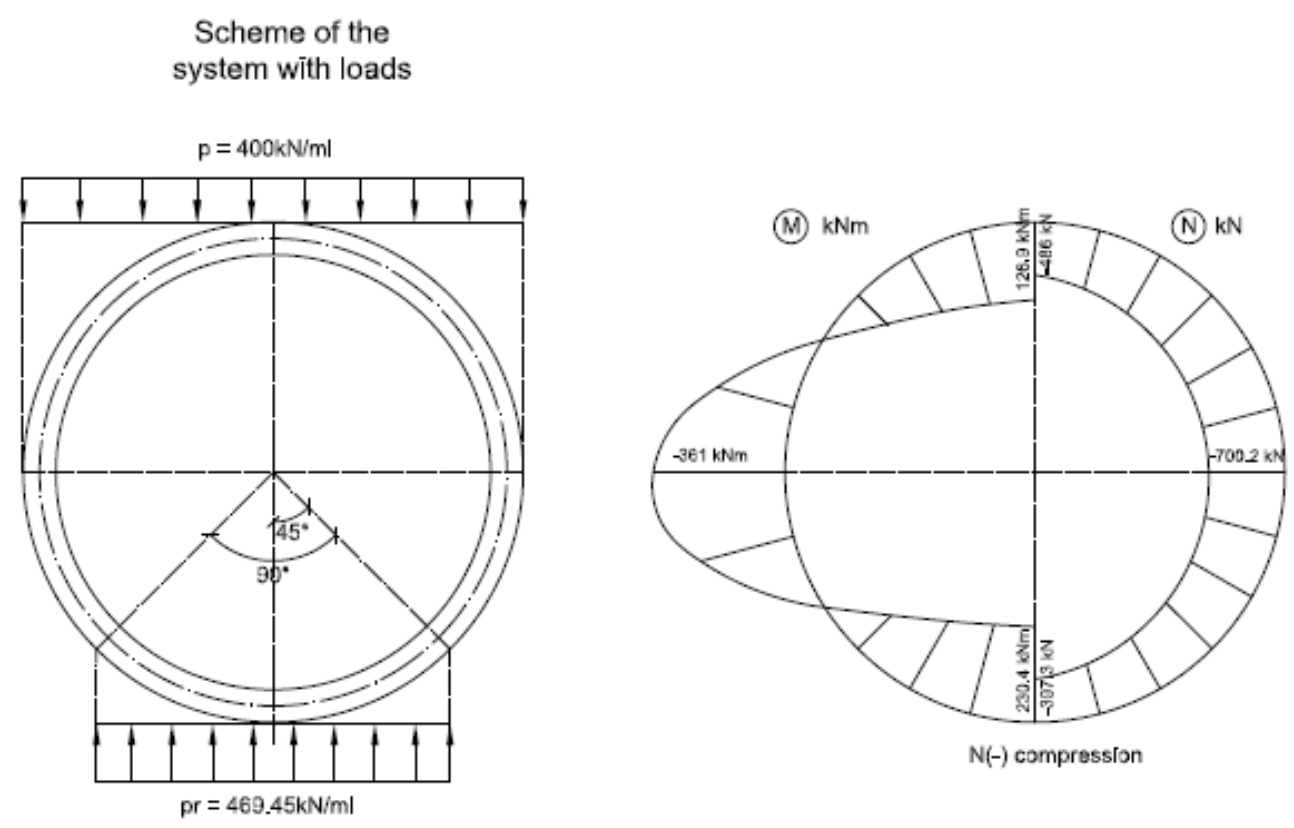

Fig.11 - Scheme for calculating by Protodiakonov method and sectional stresses (M,N) in gallery lining calculated for an uniform vertical pressure of $400 \mathrm{kN} / \mathrm{ml}$.

Table 2

Calculul carried out with Prododiakonov Method

\begin{tabular}{|c|c|c|c|c|c|c|c|c|c|}
\hline \multicolumn{4}{|c|}{$\begin{array}{c}\gamma_{\mathrm{c}}=24 \mathrm{kN} / \mathrm{m}^{3} \\
\mathrm{E}_{\mathrm{c}}=2400 \mathrm{Mpa} \\
\mu=0.2\end{array}$} & \multicolumn{3}{|c|}{$\begin{array}{c}\mathrm{M} \text { - Bending moments } \\
\mathrm{kNm}\end{array}$} & \multicolumn{3}{|c|}{$\begin{array}{l}\mathrm{N}-\text { Axial forces } \\
\mathrm{kN} \\
(-) \text { compression }\end{array}$} \\
\hline$\gamma_{\mathrm{r}}$ & $E_{\mathrm{r}}$ & $\mu$ & Protodiakonov & Key & Abutments & Apron axis & Key & Abutments & Apron axis \\
\hline $\mathrm{kN} / \mathrm{m}^{3}$ & $\mathrm{MPa}$ & & $\begin{array}{c}\text { Coefficient } \\
\mathrm{f}\end{array}$ & & & & & & \\
\hline 20 & 150 & 0.30 & 0.1 & 93.6 & -192.5 & 170 & -35.8 & -516.5 & -293 \\
\hline 20 & 300 & 0.30 & 0.2 & 19.6 & -40.3 & 35.6 & -7.5 & -108.1 & -61.3 \\
\hline 20 & 500 & 0.30 & 0.4 & 10.3 & -21.2 & 18.8 & -3.9 & -60 & -32.3 \\
\hline
\end{tabular}

The sectional stresses (M,N) from Table 2 are illustrated in figure 12 (right side) compared with their equivalents obtained in FEM analyses (left side). The aspect of the sectional stresses diagrams is identical but there are big differences between corresponding values.

Concerning bending moments $(\mathrm{M})$ the values calculated by Protodiakonov method are for $\mathrm{f}=0.1$ in rate from $-5.5 \%$ to $+90 \%$ versus their correspondents computed in FEM. For bigger Protodiakonov coefficients $\mathrm{f}=0.2 \quad 0.3$ values of $\mathrm{M}$ are always smaller than their correspondents computed in FEM in rate from $-33 \%$ to $-73 \%$.

Concerning axial forces $(\mathrm{N})$ the values calculated by Protodiakonov method are permanently much smaller than their correspondents computed in FEM. These very big differences are explained because in Protodiakonov method on gallery lining on vertical direction acts only the ground located under crumble vault distributed as uniform pressure on gallery width, neglecting structure - ground interaction.

In the case study considered in this paper for $\mathrm{f} \leq 0.075$ the height of crumble vault becomes higher than height of the ground over gallery key and consequently Protodiakonov method becomes not applicable. 

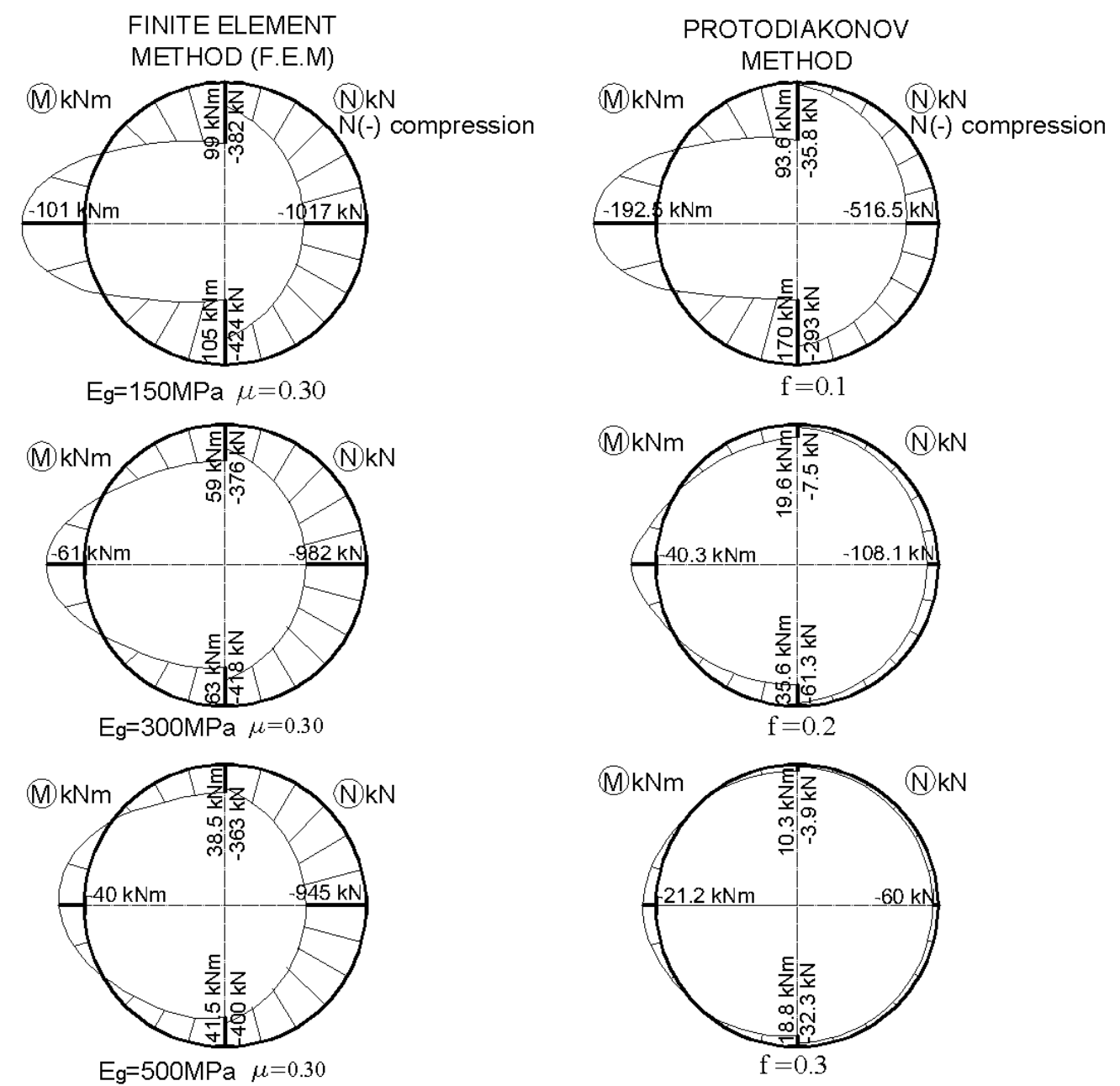

Fig.12 - Variation of sectional stresses (M,N) in gallery lining for different characteristics of the ground calculated by FEM and by Protodiakonov method.

In conclusion, Protodiakonov method leads generally to sectional stresses (M,N) in gallery lining much different than their correspondents evaluated in FEM. The bending moments (M) evaluated by both methods are comparable only for the Protodiakonov coefficients close by $\mathrm{f}=0.1$. Axial forces $(\mathrm{N})$ evaluated by Protodiakonov method are always much smaller than their correspondents evaluated in FEM.

\section{Concluding remarks}

The followings concluding remarks can be formulated based on the results of the study:

- The study had the goal to establish the area in which Protodiakonov method for calculating the galleries can be applied taking into account that currently more rigorous methods are developed based mainly on FEM.

- The sectional stresses $(\mathrm{M}, \mathrm{N})$ in a gallery lining are computed comparatively numerical by FEM considering the interaction between underground (buried) structure and surrounding ground and analytical by Protodiakonov method. The ground had successively different geotechnical characteristics with Young module from $5 \mathrm{MPa}$ to 30,000 $\mathrm{MPa}$. The analyses were performed in hypothesis of the materials linear elastic behaviour.

- The study pointed out, Protodiakonov method leads generally to sectional stresses (M.N) in gallery lining much different than those resulting in FEM analyses. $\mathrm{M}$ values evaluated by that two methods are comparable only to the Protodiakonov coefficients close by $f=0.1$. 
- Axial forces $\mathrm{N}$ values evaluated by Protodiakonov method are always much smaller than their correspondents resulted in FEM analyses. This is explained because they are computed only to rock load located under coincidence vault. If it was considered the rock weight over gallery limited by tangents to gallery abutment axial force at gallery abutment reaches 752.5 $\mathrm{kN}$, value comparable with those computed by FEM. However the values computed by FEM are bigger because the sector of ground situated over gallery gap and gallery lining are stiffer than ground lateral sectors and thus the gallery lining is loaded with loads from lateral sectors. This case is true for $\mathrm{E}_{\mathrm{r}} / \mathrm{E}_{\mathrm{c}} \leq 0.62$.

- The study is available for underground structure built so that their lining takes integral loads undeformed ground (rock) mass surrounding structure, existent before excavation. This means that temporary support of the excavation is a rigid one.

\section{References}

[1] Priscu, R. Hydraulic Constructions Vol.2 (in Romanian) Editura Didactica si Pedagogica, Bucharest, 1974.

[2] *** Zurabov, G. and Bugaeva, O. Hydropower Plant Galleries (in Russian). Moscow, 1962.

[3] Hoek, E. Rock Mechanics - an Introduction for the Practical Engineer. Part I,II and III. Mining Magazine. April, June, July, 1966

[4] Stematiu, D. Mecanica Rocilor pentru Constructii Subterane (in Romanian) Matrix Rom, Bucuresti, 2003.

[5] *** Indian Standard Code for Practice for Design of Tunnel Conveying Water. Part V. Structural Design of Concrete Lining in Soft Strata and Soils. Dee Kay Printers, New Delhi - India, 1990

[6] Yang, J.H., Wang, S.R., Wang, Y.G. and Li, C.L.Analysis of Arching Mechanism and Evolution Characteristics of Tunnel Pressure Arch. Jordan Journal of Civil Engineering, Volume 9, No.1, 2015.

[7] [Chen, Y.L.The analysis of elastic liner in a cylindrical tunnel subjected to sh-waves. Journal of the Chinese Institute Engineers, Volume 3, Issue 1, 1980.

[8] Wang, Z., Zhang, Y., Yang, C., Li, Xi-zhe. Load Bearing Arching Between Cantilever Piles and Influencing Factors. ELGE Vol.18 (2013) Bund.Z

[9] Kim, J.S., Kim, M.K. and Jung, S.D. Two-dimensional numerical model using Winkler based beam element and its application into tunnel monitoring systems. Cluster Computing, Volume 18, Issue 2, June 2015.

[10] Poterasu, V.F. Comparative study of tunnels by the boundary element method and the finite element method,Engineering Analysis. Elsevier. Volume 3, Issue 1, March, 1986.

[11] Stematiu, D. Mecanica Rocilor pentru Constructori (in Romanian) Editura Conspress, Bucuresti, 2008.

[12]*** ABAQUS 6.11/CAE Users Manual. United States of America; ABAQUS Inc., 2009. 